\title{
Kemampuan Berpikir Kritis pada Model Project Based Learning disertai STEM Siswa SMA pada Suhu dan Kalor
}

\author{
Sumardiana ${ }^{1}$, Arif Hidayat ${ }^{1}$, Parno $^{1}$ \\ ${ }^{1}$ Pendidikan Fisika-Universitas Negeri Malang
}

\begin{tabular}{l} 
INFO ARTIKEL \\
\hline Riwayat Artikel: \\
Diterima: 01-04-2019 \\
Disetujui: 18-07-2019
\end{tabular}

\section{Kata kunci:}

critical thinking skills; project based learning; STEM;

temperature and heat; kemampuan berpikir kritis; project based learning, STEM;

suhu dan kalor

\begin{abstract}
ABSTRAK
Abstract: Critical thinking skills can be grown with learning project based learning models. The purpose of this study was to analyze Critical Thinking abilities with projectbased learning (PjBL) students at temperature and heat at the high school level. This research was conducted at SMAN 2 Batu class XI. The subjects of this study were 35 students. This type of research is a mixed method embedded in experimental models. With a test of critical thinking skills the essay forms as many as 8 items. The results showed that there were differences in critical thinking of students before and later getting $\mathrm{PjBL}$ training on the material heat and temperature. The result of the research showed that students' critical thinking has increas.

Abstrak: Keterampilan berpikir kritis dapat ditumbuhkan dengan model pembelajaran project based learning. Tujuan penelitian ini adalah untuk menganalisis kemampuan berpikir kritis dengan project based learning $(\mathrm{PjBL})$ siswa pada suhu dan kalor pada tingkat SMA. Penelitian ini dilakukan di SMAN 2 Batu kelas XI. Subjek penelitian ini berjumlah 35 siswa. Jenis penelitian ini Mixed method embedded experimental model. Dengan test kemampuan berpikir kritis berbentuk essay sebanyak delapan butir. Hasil penelitian menunjukkan bahwa terdapat perbedaan keterampilan berpikir kritis siswa sebelum dan sesudah mendapatkan perlakuan PjBL pada materi suhu dan kalor. Kemampuan berpikir kritis siswa mengalami peningkatan pada setiap indikator.
\end{abstract}

\author{
Alamat Korespondensi: \\ Sumardiana \\ Pendidikan Fisika \\ Universitas Negeri Malang \\ Jalan Semarang 5 Malang \\ E-mail: ana_sumardiana@yahoo.com.id
}

Berpikir kritis merupakan tujuan utama dalam pendidikan sains. Kemampuan berpikir kritis dari sains penting diajarkan di sekolah (Ennis, 2011). Kemampuan berpikir kritis sangat penting ditanamkan dalam sains untuk diajarkan di sekolah maupun universitas (Tiruneh, De Cock, \& Elen, 2018). Kemampuan berpikir kritis dapat membantu keberhasilan pembelajaran, dalam berpikir kritis selain melibatkan proses juga melibatkan kemampuan berpikir seperti memprediksi, menganalisis, mensintesis, mengevaluasi, menalar, dan sebagainya (Tiruneh et al., 2018). Materi suhu dan kalor merupakan materi yang kaya dengan konsep. Konsepkonsep tersebut saling berkaitan, namun pemahaman siswa terkait dengan konsep tersebut masih tumpang tindih (Leinonen, Moisseev, \& Nousiainen, 2013). Misalnya, kalor dimengerti sebagai sesuatu yang bisa mengalir dari suatu benda dan meyakini bahwa kalor dan suhu adalah sinonim (Driver, Squirer, Rushworth, \& Wood-Robinson, 1994). Siswa belum bisa menjelaskan bahwa, kalor sebagai energi yang berpindah dari satu benda ke benda yang lain merupakan hasil dari perbedaan suhu, dan menghubungkan dua konsep antara energi dan suhu. Pada materi suhu dan kalor siswa menyelidiki perubahan suhu saat bervariasi dari air panas dan dingin kemudian dicampur dan bagaimana perubahannya (Henderson, Mestre, \& Slakey, 2015).

Suhu dan kalor terlihat bahwa tingkat pemahaman konsep siswa SMA mengenai konsep sangat rendah. Hal ini siswa memiliki kesalahpahaman tentang konsep (Gurcay \& Gulbas, 2018) mengamati bahwa tingkat pemahaman siswa pada konsepkonsep ini berada di bawah rata-rata. Rendahnya pemahaman konseptual siswa dapat muncul kesalahpahaman. Pembelajaran ini bertujuan untuk mengidentifikasi kesalahpahaman siswa yang muncul tentang panas dan suhu. Selain itu, pada penelitian lain menunjukkan bahwa siswa mengalami kesulitan dalam menghubungkan pengetahuan yang diperoleh selama di sekolah dengan pengalaman dalam kehidupan sehari-hari. Miskonsepsi siswa terjadi karena tidak ada hubungan antara kehidupan sehari-hari dengan pengalaman sekolah. Banyak siswa bingung tentang konsep panas dan suhu adalah hal yang sama. Siswa menghafalkan konsep ini dan tidak mampu membuat hubungan antara fenomena pengetahuan dan fisika dalam kehidupan sehari-hari. Salah satu pembelajaran yang dapat meningkatkan efektivitas siswa yaitu project based learning. Pada pendekatan pembelajaran STEM dengan menggunakan pembelajaran 6E, materi suhu dan kalor PjBL juga dapat meningkatkan literasi saintifik siswa (Khaeroningtyas, Permanasari, \& Hamidah, 2016). Selain itu, beberapa penelitian yang telah dilakukan mengintegrasikan pendekatan STEM dengan Project Based Learning (PjBL) dapat meningkatkan efektivitas, menghasilkan pembelajaran bermakna 
dan memengaruhi sikap siswa dalam penentuan karir dimasa depan (Tseng, et al., 2013). Hal ini tentu terjadi karena dalam PjBL melibatkan penyelidikan-penyelidikan ilmiah. Kegiatan belajar yang berbasis penyelidikan memungkinkan siswa memperoleh konsep ilmiah yang lebih baik. PjBL dapat membuat siswa lebih aktif dan kreatif dalam belajar. PjBL mampu meningkatkan keterampilan berpikir kritis dan pemecahan masalah.

Salah satu kompetensi dasar siswa pada konsep konveksi suhu, dan panas adalah untuk menganalisis dampak dari panas dan perpindahan panas dalam kegiatan sehari-hari. (Amalia, Sari, \& Sinaga, 2017) dengan pembelajaran Project Based Learning disertai STEM dapat meningkatkan pengalaman siswa sehingga dapat meningkatkan motivasi dan minat belajar pada siswa (Afriana, Permanasari, \& Fitriani, 2016). Penerapan pembelajaran sains pada kurikulum 2013 telah memberikan acuan dalam pemilihan model pembelajaran yang sesuai dengan pendekatan saintifik. Model pembelajaran yang dimaksud ialah Project Based Learning (PjBL). Pemilihan model pembelajaran diserahkan kepada guru dengan menyesuaikan karakteristik materi yang diajarkan. Pembelajaran berbasis proyek merupakan model pembelajaran yang berpusat pada siswa dan memberikan pengalaman belajar yang bermakna bagi siswa. Pengalaman belajar siswa maupun perolehan konsep dibangun berdasarkan produk yang dihasilkan dalam proses pembelajaran berbasis proyek (Capraro, Capraro, \& Morgan, 2013).

Pembelajaran yang sesuai untuk meningkatkan kemampuan berpikir kritis dengan menerapkan lingkungan yang membuat siswa berperan aktif adalah pembelajaran Project Based Learning. Penelitian ini dapat meningkatkan konsep-konsep fisika, mengidentifikasi berpikir kritis sebagai indikator pencapaian PjBL masa depan dan dapat membuka pengetahuan untuk diskusi tentang pembelajaran. Pembelajaran ini dapat meningkatkan kemampuan berpikir siswa. Berdasarkan penelitian terdahulu bahwa penelitian ini perlu dilakukan untuk mengetahui kemampuan berpikir kritis dengan menggunakan model pembelajaran Project Based Learning pada materi suhu dan kalor agar menghasilkan produk yang lebih bermakna.

\section{METODE}

Jenis penelitian yang digunakan adalah mixed methods desain embedded Experimental Model. Partisipan dalam penelitian ini adalah siswa SMAN 2 kelas XI IPA semester II tahun pelajaran 2018/2019. Sebelum pembelajaran PjBL dilakukan, siswa diberi soal pretest dan sesudah melakukan pembelajaran siswa diberi soal posttest. Data kuantitatif berupa hasil skor nilai pretest dan posttest. Jawaban siswa dianalisis menggunakan rubrik kemampuan berpikir kritis dengan lima indikator, yaitu reasoning, hypothesis testing, argument analysis, likelihood and uncertainty analysis, memecahkan masalah dan mengambil keputusan (Tiruneh et al., 2018).

\section{HASIL}

Jawaban siswa dalam Ketrampilan Berpikir Kritis suhu dan Kalor pada saat pretest dan posttest. Uji analisis terdiri dari uji normalitas dan uji homogenitas. Hasil uji normalitas menunjukkan bahwa dari hasil data tersebut terdistribusi normal dan juga homogen. Selanjutnya, uji t berpasangan kemudian nilai dari uji t tersebut adalah signifikansinya mendapatkan 0,00 maka nilai 0,00>0,005 untuk nilai signifikasinya sebelum dan sesudah pembelajaran Project Based Learning mengalami perbedaan. Dalam penelitian keterampilan berpikir kritis ini terdiri dari tiga sub materi yaitu suhu dan pemuaian, perubahan kalor terhadap wujud, dan perpindahan kalor. Terdapat beberapa respons jawaban siswa tentang setelah menjawab soal kemampuan berpikir kritis yang dilihat dari hasil pretest dan posttest diagram gambar 1 menunjukkan hasil kemampuan berpikir kritis masing-masing indikator kemampuan berpikir kritis mengalami peningkatan. Hal ini dapat dilihat dari hasil persentase diagram gambar 1 dan 2.

Adapun hasil statistik deskriptif disajikan pada tabel 1 yang menyatakan nilai skor minimum, skor maksimum, nilai ratarata, dan standar deviasi. Kemampuan berpikir kritis siswa tidak hanya dilihat dari hasil analisis statistik deskriptif saja, tetapi juga dilihat dari perilaku siswa dalam berpikir kritis suhu dan pemuaian. Penilaian perilaku siswa dilakukan secara pengodean uraian jawaban siswa berdasarkan hasil jawaban siswa. Berikut disajikan persentase hasil pengodean proses berpikir kritis siswa dalam kemampuan berpikir kritis suhu dan kalor.

Pada gambar 1 dan 2, diketahui bahwa banyak siswa pada soal kemampuan berpikir kritis nilai pretest lebih tinggi daripada posttest. Hasil tersebut menunjukkan bahwa terdapat peningkatan dari masing-masing indikator. Analisis keterampilan berpikir kritis yang terdiri dari penalaran, pengujian hipotesis, analisis argumen, analisis kemungkinan dan ketidakpastian, pemecahan masalah dan pengambilan keputusan dari hasil analisis data dari tiap indikator yang persentase paling tinggi adalah pemecahan masalah dan pengambilan keputusan. Dari hasil pretest dan posttest diatas menunjukkan bahwa hasil posttest mengalami peningkatan. Pada soal yang terdapat pada indikator 1 hasil pretest $10 \%$ dan posttest menjadi $70 \%$, dan soal no 2 pada indikator hasil pretest $30 \%$, posttestnya menjadi $80 \%$, dan soal no 3 pada indikator hasil pretest $10 \%$, posttestnya menjadi $80 \%$, dan soal no 4 pada indikator hasil pretest $10 \%$, posttestnya menjadi $60 \%$, dan soal no 5 pada indikator hasil pretest $30 \%$, posttestnya menjadi $80 \%$. 
Keterampilan berpikir kritis terdiri dari lima indikator, yaitu penalaran, pengujian hipotesis, analisis argumen, analisis kemungkinan dan ketidakpastian, pemecahan maslah dan pengambilan keputusan. Dari masing-masing indikator terdapat indikator pemecahan masalah dan pengambilan keputusan dapat dikategorikan tinggi begitu juga dengan indikator analisis argumen. Pada indikator dari setiap penalaran, pengujian hipotesis, dan analisis kemungkinan dan ketidakpastian dapat dikatakan sebagai kategori sedang.

Tabel 1. Statistik Deskriptif Kemampuan Berpikir Kritis Siswa

\begin{tabular}{cc}
\hline Statistik & Nilai \\
\hline Minimum & 67,62 \\
\hline Maksimum & 81,25 \\
\hline Median & 73,44 \\
\hline Standar Deviasi & 3,298
\end{tabular}

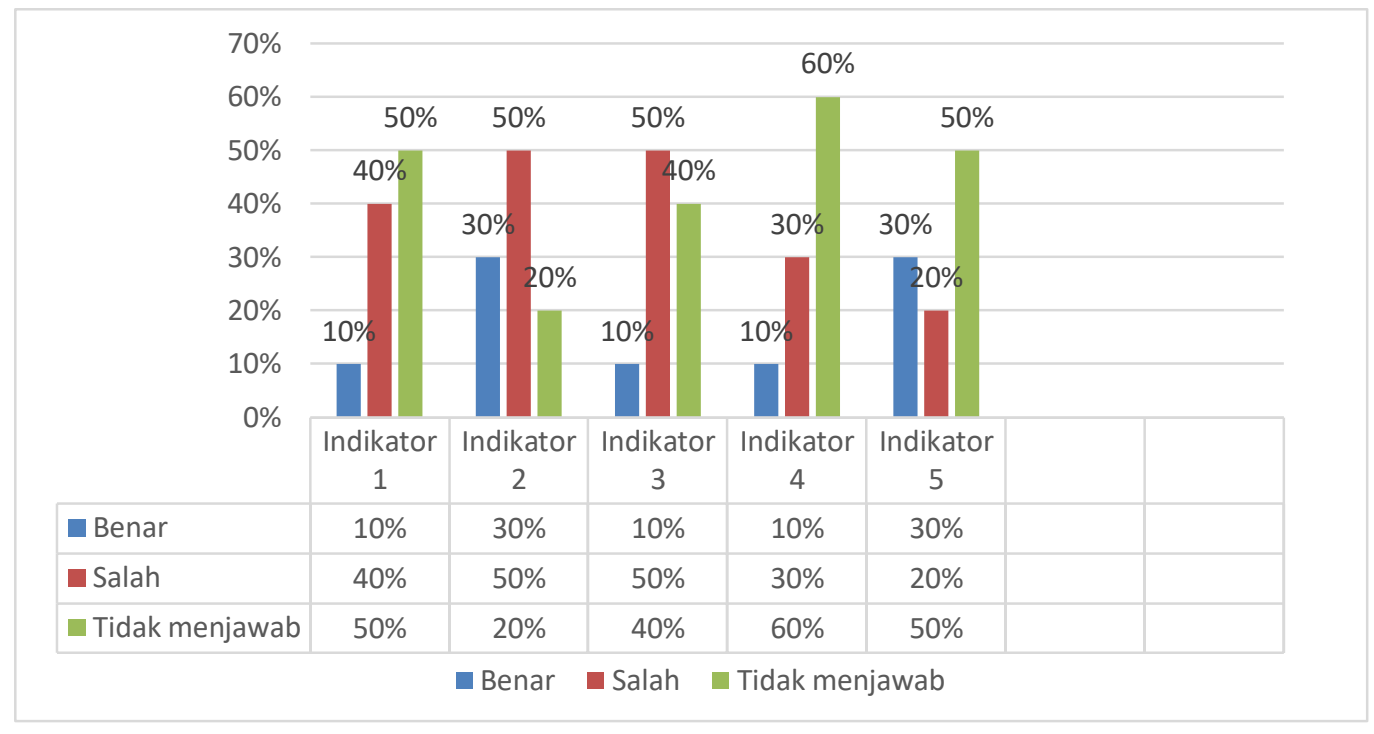

Gambar 1. Diagram Persentase Nilai Siswa pada Pretest

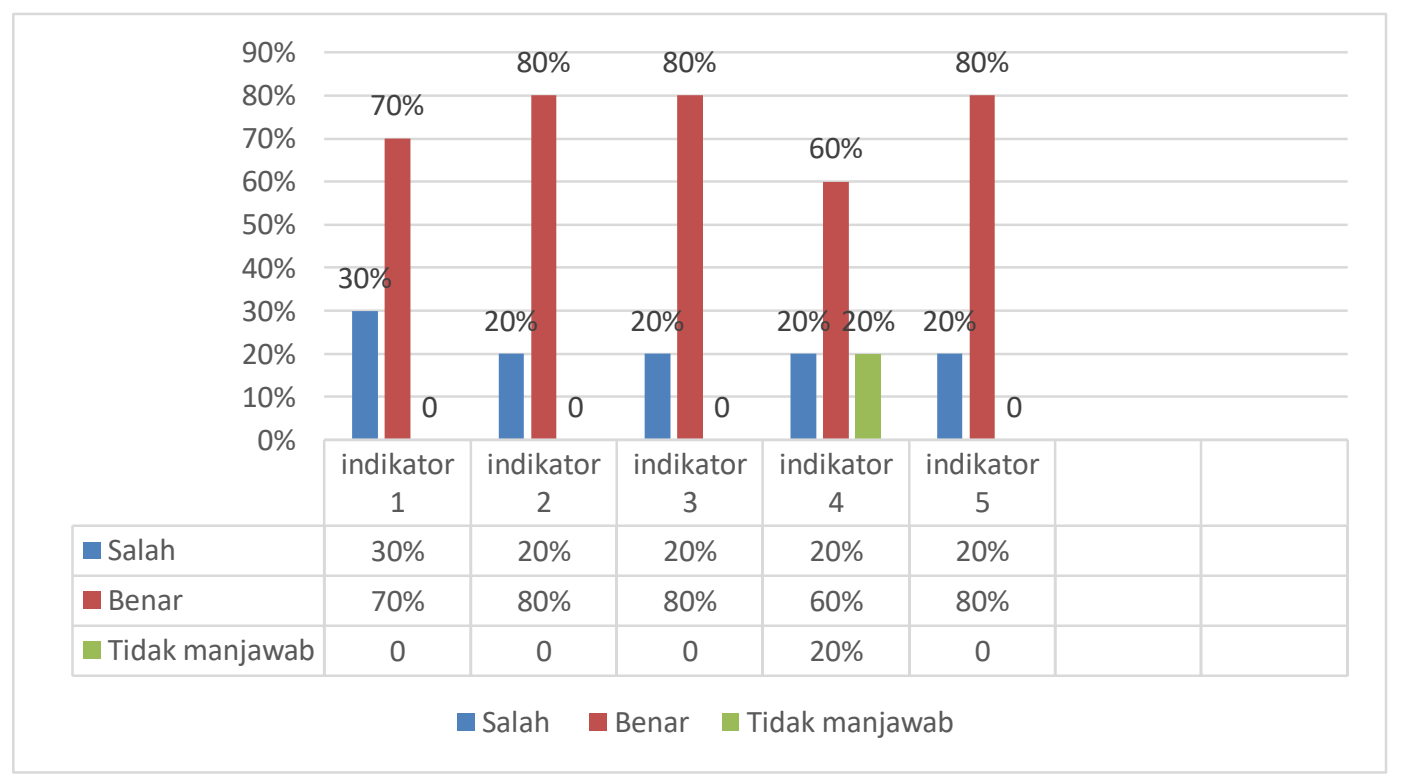

Gambar 2. Diagram Persentase Nilai Siswa pada Posttest 


\section{Laporan Hasil Proyek Siswa}

Hasil laporan proyek (proyek 1) siswa pada materi suhu dan pemuaian dan laporan pada sub materi perubahan kalor terhadap wujud (proyek II) dan pada materi perpindahan kalor (proyek III) dari hasil proyek tersebut menggambarkan hasil karya dari masing-masing kelompok yang berisi tentang teori pada suhu dan kalor, alat yang digunakan, cara membuat proyek, dan bagaimana menguji dan menganalisis hasil agar proyek yang dibuat berhasil sesuai dengan konsep suhu dan kalor.

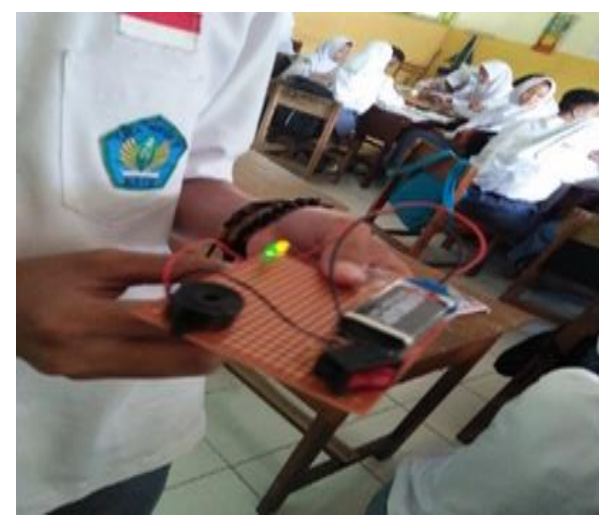

\section{Gambar 1. Alarm Sederhana Hasil Proyek Siswa}

Pada hasil proyek I siswa membuat alat alarm sederhana dimana alat dan bahannya adalah buser, lampu kecil, baterai saklar lampu mereka berhasil menunjukkan bahwa buser yang mereka gunakan dapat mengatur pemuian apabila terjadi perubahan suhu atau panas, dan dengan menggunakan lampu yang berbeda dapat berpengaruh pada suhu dari suatu benda. Hal ini sesuai dengan konsep dari suhu dan pemuaian. Pada gambar (a) menunjukkan contoh proyek siswa tentang suhu dan pemuaian.

Hasil lembar kerja siswa pada proyek 1 pada tahap pertanyaan hipotesis, siswa diberikan pertanyaan yaitu" Besaran yang dapat memengaruhi pemuaian adalah "Jawaban: yang memengaruhi pemuaian adalah panjang benda, apabila semakin panjang ukuran suatu benda padat yang dipanaskan maka semakin besar pemuaiannya”. Pada gambar 1 menunjukkan bahwa jawaban dari Lembar Kerja pada proyek Alarm kebakaran menunjukkan pada siswa dalam kemampuan berpikir kritis yang termasuk dalam indikator pengujian hipotesis dapat dikategori tinggi karena siswa tersebut mampu menyelesaikan dari permasalah tentang faktor-faktor yang dapat memengaruhi dari pemuaian dan siswa menyelesaikan permasalahan tersebut dengan baik.

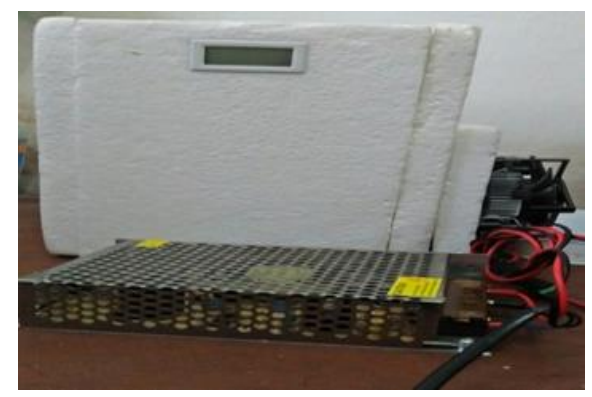

\section{Gambar 2. Kulkas Sederhana Hasil Proyek Siswa}

Pada hasil proyek II, siswa dapat menyimpulkan bahwa proyek yang mereka buat berupa kulkas sederhana filter, kipas, termometer berhasil menunjukkan bahwa dapat mengatur suhu. Selain itu, dengan pemasangan filter yang benar juga berpengaruh pada suhu dari suatu benda apabila pemasangan filtier salah maka suhu dari suatu benda akan menjadi panas. Hal ini sesuai dengan konsep dari perubahan kalor terhadap wujud. Pada gambar 2 menunjukkan contoh proyek siswa tentang perubahan kalor terhadap wujud.

Hasil Lembar Kerja Siswa proyek II "Bagaimana menyelesaikan masalah yang mengenai kosep atau prinsip yang melatarbelakangi permaslahan tentang perubahan kalor terhadap wujud serta menuliskan konsep secara matematisnya. Jawaban siswa: Kalor panas dapat menaikan suhu suatu zat yang berdampak terhadap terhadap perubahan wujud suatu zat, melebur dan menguap memerlukan kalor, untuk melebur bongkahan es atau menguapkan air diperlukan kalor. Hasil dari lembar kerja siswa menunjukkan bahwa siswa belum mampu menyelesaikan masalah dari suatu keputusan yang terdapat pada indikator 
kemampuaan berpikir kritis, gambar (b) menunjukkan bahwa jawaban dari Lembar Kerja pada proyek kulkas sederhana menunjukkan bahwa Kemampuan Berpikir Kritis siswa termasuk dalam indikator mampu memecakan masalah dan mengambil keputusan dapat dikategorikan sedang karena siswa hanya mampu menyelesaikan masalah, tetapi masih belum menyelesaikan sesuai dengan konsep matematisnya.

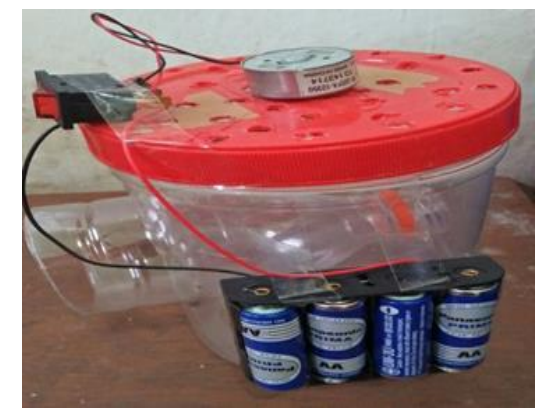

\section{Gambar 3. AC Sederhana Hasil Proyek Siswa}

Pada hasil proyek III, siswa dapat menyimpulkan bahwa proyek yang mereka buat berupa AC sederhana berhasil menunjukkan bahwa dapat mengatur suhu dan pemasangan baterai yang benar juga dapat berpengaruh pada suhu dari suatu benda. Namun, apabila pemasangan baterai dan dinamonya salah maka suhu dari suatu benda akan menjadi panas. Hal ini sesuai dengan konsep dari perpindahan kalor, pada gambar (c) menunjukkan contoh proyek siswa tentang perpindahan kalor.

Hasil Lembar Kerja Siswa proyek III. Pada tahap ini, siswa diberikan permasalahan tentang "Bagaimana mendeskripsikan masalah yang dihadapai tentang perpindahan kalor. Jawaban : kenaikan suhu yang menyebabkan udara terasa panas dan dengan AC sederhana dapat membantu“. Hal ini menunjukkan bahwa jawaban dari Lembar Kerja pada proyek AC (Air Conditioner) sederhana termasuk dalam indikator penalaran kategori tinggi.

\section{PEMBAHASAN}

Kemampuan berpikir kritis siswa pada materi suhu dan kalor menunjukkan bahwa siswa mengalami perubahan yang sangat baik setelah mengerjakan proyek. Hal ini dapat kita ketahui dari hasil rata-rata skor keterampilan berpikir kritis yang memiliki nilai signifikansi dengan indikator berpikir kritis yang nilai posttestnya lebih tinggi daripada pretest. Ketika posttest mengalami peningkatan daripada pretest, hal ini menunjukkan bahwa persentase mencapai peningkatan ketika menunggunakan model PjBL. Model pembelajaran ini dapat meningkatkan keterampilan berpikir siswa dalam menyelesaikan berbagai permasalahan pada fisika. Dengan menggunakan pembelajaran PjBL dapat meningkatkan keterampilan berpikir kritis pada siswa. Penelitian ini sama dengan penelitian yang dilakukan oleh (Afriana, Permanasari, \& Fitriani, 2016; Luthvitasari \& Linuwih, 2012) pembelajaran $\mathrm{PjBL}$ dapat meningkatkan keterampilan berpikir kritis.

Ada beberapa indikator berpikir kritis yang harus dicapai oleh siswa, yaitu reasoning, hipothesis testing, argument analysis, likelihood and uncertainty analysis, memecahkan masalah dan mengambil keputusan (Tiruneh, et al., 2018). Berdasarkan dari indikator hasil analisis menunjukkan bahwa hasil persentase pretest mencapai $10 \%$ dan posttest $70 \%$. Hal ini menunjukkan bahwa hasilnya meningkat karena siswa mampu menyelesaikan, baik proyek maupun lembar kerja dengan baik, tetapi masih belum mecapai $100 \%$. Hal ini disebabkan karena siswa pada indikator tersebut belum lengkap dalam menjelaskan tentang perpinndahan kalor secara konveksi. Pada indikator hipotesis testing, argument analysis hasil pretest $50 \%$ dan pada posttest menjadi $80 \%$. Hal ini menunjukkan bahwa hasilnya meningkat, indikator tersebut masih belum mencapai $100 \%$ karena pada soal indikator tersebut belum tepat dalam menentukan pernyataan siswa mengangap bahwa suhu dan kalor itu memiliki pengertian yang sama. Pada indikator likelihood and uncertainty analysis hasil pretest $50 \%$ dan pada posttest menjadi $80 \%$ hal ini menunjukkan bahwa hasilnya meningkat, tetapi masih belum mencapai $100 \%$ disebabkan karena pada indikator soal, siswa masih belum lengkap dalam menjelaskan pemuaian yang terjadi pada kabel listrik. Pada indikator analisis kemungkinan dan ketidakpastian hasil pretest $10 \%$ dan posttest $60 \%$ pada indikator ini juga terdapat $20 \%$ siswa yang tidak menjawab, sedangkan pada indikator memecahkan masalah dan mengambil keputusan hasil pretest $30 \%$ dan posttest $80 \%$ hasil ini masih dikategorikan tinggi, tetapi belum mencapai $100 \%$ karena masih banyak siswa yang kurang dalam menyelesaikan soal pemuaian, mereka hanya menjawab panjang awalnya saja.

Hasil ini menunjukkan bahwa rata-rata nilai siswa mampu menjawab dan dengan berpikir secara lebih baik dari sebelumnya dan dapat meningkatkan pengetahuan yang baru, kebanyakan siswa mampu menjawab soal sampai tahap indikator, memecahkan masalah, dan mengambil keputusan. Setelah itu, dari hasil analisis laporan siswa pada pembuatan proyek menunjukkan bahwa pada kegiatan pembelajaran pada materi suhu dan kalor siswa lebih aktif dalam mencari sumber sendiri. 
Ketika dalam pembuatan proyek siswa lebih aktif sehingga mendapatkan pengetahuan baru yang mereka terapkan dalam kehidupan nyata sehingga pembelajaran yang dilakukan bermakna. Dengan pembuatan proyek siswa dapat menumbuhkan konsep-konsep pada materi suhu dan kalor agar siswa lebih aktif dalam mengali dari berbagai informasi. Penelitian ini menunjukkan hasil yang sama seperti penelitian (Anita, 2017) bahwa model pembelajaran dengan model PjBL siswa lebih paham dengan materi yang diajarkan dengan memberikan tugas siswa dituntut dalam berpikir untuk menyelesaikan berbagai permasalahan di dalam kelas dengan cara berkelompok, agar siswa memiliki pengetahuan yang lebih luas.

\section{SIMPULAN}

Berdasarkan dari analisis hasil terdapat perbedaan yang signifikan kemampuan berpikir kritis kelas XI IPA di SMAN 2 Batu ketika sesudah dan sebelum pembelajaran dengan menggunakan model PjBL pada materi suhu dan kalor $(0,01<0,05)$. Hasil ini menunjukkan bahwa terdapat pengaruh antara pembelajaran Project Based Learning dengan STEM terhadap kemampuan berpikir kritis, dimana pada saat pretest dan posttest nilai siswa mengalami peningkatan, sedangkan pada nilai Ngain sebesar 0,432451. Hasil ini menunjukkan bahwa nilai siswa mengalami peningkatan. Kemampuan berpikir kritis siswa pada saat pretest dan posttest banyak mengalami peningkatan.

\section{DAFTAR RUJUKAN}

Afriana, J., Permanasari, A., \& Fitriani, A. (2016). Penerapan Project Based Learning Terintegrasi STEM untuk Meningkatkan Literasi Sains Siswa Ditinjau dari Gender. Jurnal Inovasi Pendidikan IPA, 2(2), 202-212. https://doi.org/https://doi.org/10.21831/jipi.v2i2.8561

Amalia, R., Sari, I. M., \& Sinaga, P. (2017). Students' Mental Model on Heat Convection Concept and its Relation with Students Conception on Heat and Temperature. Journal of Physics: Conference Series, 812(1), 12092. https://doi.org/https://doi.org/10.1088/1742-6596/812/1/012092

Anita, I. W. (2017). Implementasi Pembelajaran Berbasis Proyek untuk Menumbuhkan Kemampuan Berpikir Kreatif Matematis Mahasiswa. JPPM (Jurnal Penelitian dan Pembelajaran Matematika), 10(1).

Capraro, R. M., Capraro, M. M., \& Morgan, J. R. (2013). STEM Project-Based Learning: An Integrated Science, Technology, Engineering, and Mathematics (STEM) Approach. Springer Science \& Business Media.

Driver, R., Squirer, A., Rushworth, V., \& Wood-Robinson, M. (1994). Making Sense of Secondary Science: Research into Science Ideas. London \& New York: Routledge.

Ennis, R. H. (2011). Ideal Critical Thinkers are Disposed to. Inquiry: Critical Thinking Across the Disciplines, $26(2), 4$. https://doi.org/https://doi.org/10.5840/inquiryctnews201126214

Gurcay, D., \& Gulbas, E. (2018). Determination of Factors Related to Students' Understandings of Heat, Temperature and Internal Energy Concepts. Journal of Education and Training Studies, 6(2), 65-72. https://doi.org/https://doi.org/10.11114/jets.v6i2.2854

Henderson, C., Mestre, J. P., \& Slakey, L. L. (2015). Cognitive Science Research can Improve Undergraduate STEM Instruction: What are the Barriers? Policy Insights from the Behavioral and Brain Sciences, 2(1), 51-60.

Khaeroningtyas, N., Permanasari, A., \& Hamidah, I. (2016). STEM Learning in Material of Temperature and its Change to Improve Scientific Literacy of Junior High School. Jurnal Pendidikan IPA Indonesia, 5(1), 94-100.

Leinonen, J., Moisseev, D., \& Nousiainen, T. (2013). Linking Snowflake Microstructure to Multi - Frequency Radar Observations. Journal of Geophysical Research: Atmospheres, 118(8), 3259-3270. https://doi.org/https://doi.org/10.1002/jgrd.50163

Luthvitasari, N., \& Linuwih, S. (2012). Implementasi Pembelajaran Fisika Berbasis Proyek terhadap Keterampilan Berpikir Kritis, Berpikir Kreatif, dan Kemahiran Generik Sains. Journal of Innovative Science Education, 1(2).

Tiruneh, D. T., De Cock, M., \& Elen, J. (2018). Designing Learning Environments for Critical Thinking: Examining Effective Instructional Approaches. International Journal of Science and Mathematics Education, 16(6), 1065-1089. https://doi.org/https://doi.org/10.1007/s10763-017-9829-z

Tseng, H. W., Vishnubhotla, S., Hong, M., Wang, X., Xiao, J., Luo, Z.-Q., \& Zhang, T. (2013). A Single Channel Speech Enhancement Approach by Combining Statistical Criterion and Multi-Frame Sparse Dictionary Learning. Interspeech, 451-455. 